\title{
A Review on Epidemiology of Hydatidosis in Livestock and Humans in South Sudan
}

\author{
Erneo B. Ochi", David A. Akol, Yatta S. Lukaw \\ University of Juba, College of Natural Resources and Environmental Studies, \\ Juba South Sudan
}

\begin{abstract}
Hydatidosis is one of the neglected tropical diseases of public health importance causing socioeconomic impacts on the livelihoods of pastoralist communities in the rural areas and the urban population in some areas at the global level. This review highlights on the epidemiology of hydatidosis and its public health importance such that strategic control measures are developed for sustainable rural development in South Sudan. Large scores of people are associated with cattle directly or indirectly for improving their livelihoods and enhancing food and nutrition security in South Sudan. Livestock are infected through the ingestion of contaminated pasture with the feces of infected dogs. Dogs usually become infected by ingestion of contaminated meat of cattle, sheep and goats with hydatid cysts. Humans acquire infection by ingestion of hydatid cysts or consumption of raw and undercooked infected meat of cattle, sheep and goats. Echinococcus granulosus and E. multilocularis are the most zoonotic and pathogenic species of Echinococcus and the adult tape-worms usually inhabit in the intestine of dogs. The Mundari tribesmen of Terekeka County, and both the Bouya and Toposa of Greater Kapoeta are the most affected communities with hydatidosis in South Sudan. Such a review is imperative for understanding and providing public awareness on the importance of extension delivery services and health education for prevention and control of the disease among the vulnerable poor rural pastoralist communities in South Sudan.
\end{abstract}

Keywords: Hydatidosis; Echinococcus granulosus; Livestock; Public Health; Human; Dogs; South Sudan.

\section{INTRODUCTION}

Hydatidosis or cystic echinococcosis (CE) is one of the neglected tropical diseases of public health importance (Ahmed et al., 2011; Omar et al., 2011). The disease is caused by larval stage of the Genus: Echinococcus of the Family: Taeniidae (Soulsby, 1986) causing considerable economic losses to slaughtered herbivores in Iran (Ahmadic and Meshkerkar, 2011) and South Sudan (Ochi et al., 2015). Moreover, the disease is of paramount importance due to its wide geographical distribution, public health and economic impacts on livestock industry (Torgerson, 2013). A considerable economic loss in the livestock industry causing reduction in animal production was reported by Romazanov (1983) and Polydorou (1981). Such losses are of special significance in countries of low economic input having particular importance in sheep and goats production (Torgerson and Budke, 2003).

Human hydatidosis is associated with several risk factors including the prevailing specific sociocultural, environmental and epidemiological facets. Evidence has shown that human behaviours play significant roles in the epidemiology and transmission cycle of the disease which differs between the dogs and their normal intermediate hosts (Ibrahim, 1990). Dogs act as definitive hosts which eventually pass eggs to the environment and these eggs are ingested by cattle, sheep and goats as intermediate hosts during grazing time (Soulsby, 1986). However, poor hygienic practice remains a major problem for the control of the disease, particularly in the remote rural areas in South Sudan. Moreover, the nomadic and socio-cultural activities are still practiced by the pastoralist and agropastoralist communities in the country which might have aggravated disease prevalence in some rural areas. Furthermore, little studies have been conducted with regard to public health importance of hydatidosis in post-independent South Sudan.

This review aimed at highlighting on the epidemiology of hydatidosis and the public health importance of the disease such that control strategies could be prioritized by key stakeholders in South Sudan. 


\section{EPIDEMIOLOGY OF HYDATODIS}

\subsection{Etiology of Hydatidosis}

Hydatidosis is caused by hydatid cyst which is the larval stage of the tapeworm, Echinococcus granulosus (Soulsby, 1986). World Health Organization (WHO) designated CE for the disease caused by E. granulosus and Alveolar Echinococcosis (AE) for the disease caused by E. multilocularis .Both E. granulosus and E. multilocularis are the most important zoonotic and pathogenic species to humans and other domesticated animals (da Silva, 2010; Magambo et al., 2006). Whereas the other form of hydatidosis caused by E. oligarthrus and E. vogeli is referred to as polycystic echinococcosis (PE) (Eckert and Deplazes, 2004; Macpherson et al., 2003). E. granulosus is approximately 2 to $7 \mathrm{~mm}$ while E. multilocularis is often smaller measuring $4 \mathrm{~mm}$ or less. Meanwhile, E. vogeli is measured up to $5.6 \mathrm{~mm}$ long compared to $2.9 \mathrm{~mm}$ long in case of E. oligarthrus. Additionally, the cysts of $E$. multilocularis are characterized by an ultra-thin limiting membranes and the germinal epithelium may bud externally. E. granulosus cysts are unilocular with full- fluid while E. multilocularis cysts are multilocular containing little fluid. E. vogeli hydatid cysts are large, polycystic and filled with fluid (CDC, 2013).

Camel genotype E. canadensis (G6) of E. granulosus is the most prevalent strain endemic in camels, goats, and cattle as well as humans, while cattle strain (G5) is confined to cattle in the Sudan (Dinkel et al.,2004). Moreover, the common sheep strain (G1) seemed to be the principal genotype affecting humans in sub-Saharan Africa. However, G6 strain of E. canadensis was identified from human patients in areas where transmission cycle for the camel genotype exists worldwide (Ahmadic and Meshkerkar, 2011). The sheep strain proved to be the most common genotype of E. granulosus affecting sheep, cattle, goats and occasionally camels. Moreover, the camel genotype was found to cause infection in both sheep and cattle, but it was reported that camels could be e infected with the camel genotype. Any, both sheep and camel strains could be readily differentiated only based on hook morphology (McManus, 2010).

\subsection{Mode of Transmission}

Infection of cattle, sheep and goats with tapeworm eggs causes hydatid cysts in vital organs including the liver and lungs (Better Health Fact, 2014). However, human can be infected by ingesting tape worm eggs passed from infected carnivores. It occurs most frequently when individuals handle or contact infected dogs or other carnivores inadvertently ingest food or drink water contaminated with fecal materials containing tape worm eggs (Ahmed et al., 2011).Transmission of hydatidosis to intermediate hosts takes place through the ingestion of eggs with contaminated food or water. The definitive hosts are infected by the means of eating infected cyst-containing organs condemned at the slaughter houses/abattoirs. Humans are accidental intermediate hosts that become infected by handling soil, dirt or animals' hair that contains eggs. No biological or mechanical vectors for the adults or larval forms of any Echinococcus species found. However, carrion birds, coprophagic flies and other arthropods can act as mechanical vectors for the eggs (CDC, 2013).

\subsection{Geographical Distribution}

Hydatidosis due to E. granulosus is commonly prevalent in sheep-raising areas of the Mediterranean, Australia, New Zealand, South Africa, South America and the Middle East including Saudi Arabia (Toulah et al., 2012). In Africa, the disease is reported more commonly in cattle raised in a free range associated intimately with dogs (Abebe and Yilma, 2013). Although, hydatidosis was first reported in Sudan in 1908, a prevalence rate of $86.4 \%$ due to canine echinococcosis was revealed in Malakal, southern Sudan in 1962 (Eisa et al., 1962). Greater Kapoeta of Eastern Equatoria State is reported as one of the endemic areas of hydatidosis in South Sudan. The prevalence of $4.3 \%$ in goats in the Toposa land and Didinga hills of the Greater Kapoeta (Magambo et al., 1997) and of 2\% and 3\% in humans in the Bouya and Toposa communities, respectively was documented (Magambo et al., 1996). Recent investigations undertaken among Mundari-tribesmen of the then Terekeka County Central Equatoria State have revealed human hydatidosis (Stewart et al., 2013).

\subsection{Diagnosis of Hydatidosis}

Case history of raw or undercooked beef consumption along with clinical signs is indicative of human hydatidosis. However, ultrasonography made detection of Hydatid cyst in the human body become feasible. In East Africa such initiative was made among pastoralists using an ultrasound scanning 
(Macpherson et al., 1989). In a hospital based-study in Nigeria, hydatidosis was shown to be $5.1 \%$ of patients having ultrasonography features of intra-abdominal hydatidosis, while in Burkina Faso, $0.007 \%$ prevalence in human was reported (Ahmed et al., 2011). A systematic sonographic abdominal examination performed in Terekeka County had shown the endemicity of hydatidosis among the pastoralist communities (Stewart et al., 2013). In an abdominal ultrasound made to a rural based-patient in Juba ,multiple loculated cysts throughout the abdomen was revealed, suggesting a secondary peritoneal hydatidosis (Thomas et al., 2015).

Generally speaking, a lack of basic medical facilities and diagnostic tools might have exacerbated the burden of hydatidosis throughout East African countries (Omar et al., 2011). Nevertheless, conventional parasitological techniques for eggs detection are used to diagnose E. granulosus in dogs. Moreover, an antigen capture enzyme linked immunosorbent assay (ELISA) in dog's faecal samples has been developed and reported to be of high sensitivity and specificity of 85\% (Abbasi et al., 2003; Allan and Craig ,1989). Serological techniques show no high sensitivity and specificity in human hydatidosis and some patients might produce no marked antibody response (Lorenzo et al., 2005). The specificity for CE could be problematic due to cross- reaction with Taenia solium and T. saginata. Nevertheless, positive sera can further be confirmed using western blotting ( Logar et al., 2008) .Furthermore, molecular techniques using polymerase chain reaction (PCR) and real time PCR could be employed for diagnosis of hydatid cyst infection from meat samples (Eckert and Deplazes,2004). But, the most reliable diagnostic method is the detection of hydatid cyst during meat inspection (Eckert et al., 2001) .Hence, the presence of hydatid cysts in internal organs is a very important diagnostic tool which confirms the disease.

\subsection{Treatment of Hydatidosis}

Treatment of hydatidosis in humans depends on the site and size of hydatid cyst(s) in the body (Sinan et al., 2002).Generally it is acceptable that medical means and surgical removal of the cyst is promising. It appears that the removal of the cyst contents and the introduction of an anthelminthic chemotherapeutics into the cyst under ultrasonography guidance through puncture, aspiration, injection, and re-aspiration (PAIR) is one of the options. However, the modified version of percutaneous aspiration of cyst content (PEVAC) is safe and effective option to surgical interference (Eckert and Deplazes, 2004; Hatipoglu et al., 2015).

\subsection{Prevention and control of Hydatidosis}

Since prevention is better than cure, it is therefore better to stop the occurrence of disease before it could inflict considerable damages that require more costs and energy to eradicate it. The control of hydatidosis involves the elimination of hydatid tapeworms from dogs by carrying out recommended control measures. The infection of dogs with a tapeworm, and the dissemination of the disease to the other animals including human subjects can be prevented (CDC, 2013; Katunguka and Rubaire, 2008). Vaccination of sheep with an E. granulosus recombinant antigen (EG95) offers encouraging prospects for prevention and control. Small-scale EG95 vaccine trials in sheep indicate high efficacy and safety with vaccinated lambs. Such field trials in New Zealand, Australia, Italy and China had a high protection rate of more than 95\% for at least one year (Lightowlers et al., 1996; Lightowlers et al., 2000). As such a programme combining vaccination of lambs, de-worming of dogs and culling of older sheep could lead to elimination of human hydatidosis in less than a decade. Moreover, thorough cooking or freezing of meat should be made to prevent hydatidosis in humans. But such preventive measures need provision of quality health education and veterinary extension services to the poor rural people including the pastoralists as well as the peri-urban communities. In Ethiopia, bordering South Sudan to the East it was commended that initiation of immediate control strategies based on the social, cultural and economic grounds of people, besides public education on the habit of feeding condemned organs to dogs is commendable (Guadu et al., 2013). Hence, similar preventive measures seem to be promising and applicable to South Sudan under similar conditions to reduce and mitigate economic losses in humans and animals.

\section{ECONOMIC IMPORTANCE OF HYDATIDOSIS}

Hydatidosis is a disease of major economic importance in both humans and animals (Torgerson and Budke, 2003). The direct economic losses due to hydatid cyst infection in livestock are due to condemnation of carcass and visceral organs including the liver lungs, spleen, heart and kidneys (Budke et al.,2006). Moreover it causes retarded growth, reduced performance, reduced milk and 
meat yield as well as reduced to poor quality of wool, decreased hide and skin value and reduced birth rate (Moro,2006;Torgerson and Budke, 2003; Torgerson and Macpherson,2011).

In humans, the economic loss is associated with the direct monetary loss due to diagnosis, hospitalization, and surgical interference or percutaneous treatments. Therapies, post-treatment care and travel for both patient and family members and other indirect costs, which may be mortality and suffering. In addition to economic and social consequences of disability associated with undiagnosed and, therefore, untreated cases, there is also loss of working days or " production " and abandonment of farming or agricultural activities by affected or at-risk persons need to be considered. Furthermore, in most reports, between $1 \%$ and $2 \%$ of CE cases are fatal (Torgerson et al., 2003) .Even without correcting for the underreporting of human CE, the disease has substantial global impact in terms of disability adjusted life years (DALYs) and monetary losses. For example, in the North African countries, the cost to human health treatment and animal losses was estimated at US\$ 60 million per year (Budke et al,.2006). However, it seems that echinococcosis has not yet attracted the attention and spotlight of governments or regional authorities (Craig et al., 2007). This could be due to difficulty in diagnosis and treatment of the disease, its occurrence in resource poor persons who usually interact with domestic dogs and lack of cooperation between medical and veterinary sectors (Craig et al., 2007).

\section{Public Health Importance of Hydatidosis}

The zoonotic importance of hydatidosis usually lies in its public health problem in various geographical areas at the global level, particularly in Asia, South America, Central America and Africa (McManus et al., 2003). Moreover, the disease has been re-emerged in several western countries (Eckert et al., 2000; Thompson et al., 2001). Hydatidosis is characterized by the presence of cysts containing numerous tiny protoscoleces that most often develop in the visceral organs, CNS and skeletal system as well as thyroid glands, subcutaneous tissues, body cavity and musculature (Abebe and Yilma, 2013). The incubation period for all species of Echinococcus varies from months to years or even decades. It largely depends on the site and speed of the cyst development in the body (Katunguka and Rubaire, 2008). Hydatid cysts are often fertile in humans, and numerous observations indicate that the high number of cases may be due to increased infectivity or pathogenicity of $E$. granulosus sansu lato. Asymptomatic infection often predominates unless other mechanical complications including rupture, compression of vital structures and haemorrhage occur. This could be due to evasion of host immunity by the parasite (CDC, 2013).

In human hydatidosis, E. granulosus, E. multilocularis, E. oligarthrus and E. vogeli are localized in the liver , the lungs and kidneys in 75\%, 5-15\% and 10-20\% of cases respectively .Let alone other organs including the spleen, brain and heart. In the patients infected with hydatidosis due to $E$. granulosus, the disease develops as a slow-growing mass or cysts in the body. The disease is not apparent to livestock keepers but it is of considerable economic and public health importance (Ahmadic and Meshkerkar, 2011). The incidence of human hydatidosis in any country is closely related to the prevalence of the disease in domestic animals. The highest prevalence has been found where there is a large population of dogs and high sheep production (Khuror, 2002). In Turkana, Kenya, the prevalence of human hydatidosis was $2.5 \%$, however, a survey based study showed a prevalence of 2\% (Njoroge et al., 2001). In central Sudan, an ultrasound survey in two different localities showed prevalence between $0.3 \%$ and $0.8 \%$ (Elmahdi et al.,2004) as opposed to 0.7\% among Mundari tribesmen of Terekeka County South Sudan (Stewart et al., 2013).

\section{Conclusion}

Hydatidosis is one of the most important diseases of public health importance in South Sudan .This is mainly due to nomadism and consumption of raw and partially cooked meat. Hence, a strict inspection of meat at slaughter houses and the access of livestock to contaminated pasture with the feces of dogs are imperative as the major preventive and control measures. Health education and quality veterinary extension services are needed to avoid infection in humans among the poor rural communities in South Sudan.

\section{ACKNOWLEDGEMENTS}

We are indebted to University of Juba for providing a moral support in publishing review articles to strengthen the University library with publications of socioeconomic priority in South Sudan. 


\section{REFERENCES}

[1] Abbasi, I., Branzburg, A., Campos-Ponce, M., Hafez, S.K.A., Raoul, F., Craig, P.S., and Hamburger, J. (2003). Copro-diagnosis of Echinococcus granulosus infection in dogs by amplification of a newly identified repeated DNA sequence. The American Journal of Tropical Medicine and Hygiene, 69(3):324-330.

[2] Abebe, F. and Yilma, J. (2013). Estimated annual economic loss from organs condemnation, decreased carcass weight and milk yield due to bovine hydatidosis. Ethiop. Vet. J., 16(2): 1-14.

[3] Ahmadic, N.M. and Meshkerhar, M (2011). An abattoir- based study on the prevalence and economic losses due to Cystic Echinococcosis in slaughtered herbivores in Ahwaz, southwestern Iran. J. Helminthol., 85: 33-39.

[4] Ahmed, M.E., Abdelrahim, M.I., Fatima M. Ahmed (2011). Hydatid disease, a morbid drop needs awareness. Ann. Saudi Med. J., 122:56-64.

[5] Allan, J. and Craig, P. (1989). Coproantigens in gut tapeworm infections: Hymenolepis diminuta in rats. Parasitology Research, 76(1): 68-73.

[6] Better Health Fact (2014). Hydatid Disease, retrieved 12 May 2014

[7] Budke, C.M., Deplzes, P. and Torgerson, P.R. (2006).Global socio-economic impact of Cystic Echinococcosis. Emerging Infectious Disease, 12(2): 296-303.

[8] CDC (2013). Hydatid Disease, retrieved 20 March 2014.

[9] Craig, P.S., Budke, C.M., Schantz, P.M.., Li, T., Qiu, J., Yang, Y. and Ito, A. (2007). Human echinococcosis: a neglected disease, Tropical Medicine and Health, 35(4): 283-292.

[10] da Silva, A.M. (2010). Human echinococcosis: a neglected disease. Gastroenterology Research and Practice, 2010.

[11] Dinkel, A., Njoroge, E. M., Zimmermann, A., Wälz, M., Zeyhle, E., Elmahdi, I. E. and Romig, T. (2004). A PCR system for detection of species and genotypes of the Echinococcus granulosuscomplex, with reference to the epidemiological situation in eastern Africa. International Journal for Parasitology, 34(5): 645-653.

[12] Eckert, J. and Deplazes, P. (2004). Biological, epidemiological, and clinical aspects of echinococcosis, a zoonosis of increasing concern. Clinical Microbiology Reviews, 17(1): 107135.

[13] Eckert, J., Conraths, F. and Tackmann, K. (2000). Echinococcosis: an emerging or re-emerging zoonosis? International Journal for Parasitology, 30(12):1283-1294.

[14] Eckert, J., Deplazes, P., Craig, P., Gemmell, M., Gottstein, B., Heath, D. and Meslin, F. (2001). Echinococcosis in animals: clinical aspects, diagnosis and treatment. WHO/OIE manual on echinococcosis in humans and animals: a public health problem of global concern, 72-99.

[15] Eisa, A.M., Mustafa, A.A. and Soliman, K.N. (1962). Preliminary Report on Cysticercosis and hydatidosis in Southern Sudan. Sud. J. Vet. Sci., 3:97-108.

[16] Elmahdi, I., Ali, Q., Magzoub, M., Ibrahim, A., Saad, M. and Romig, T. (2004). Cystic echinococcosis of livestock and humans in central Sudan. Annals of Tropical Medicine and Parasitology, 98(5):473-479.

[17] Guadu, T., Gebremicael, Y. and Chanie, M. (2013). Economic and Zoonotic Importance of Bovine Hydatidosis in Shire Municipal Abattoir, North West Zone, Tigary Region, Ethiopia.

[18] Hatipoglu, S., Akbulut, S., Gulacti, U., Lok, U. and Hatipoglu, F. (2015). Primary subcutaneous hydatid cyst on the incisional scar following open cholecysectomy :A rare case report and review of the literature. Acta Medica, 31: 329e.

[19] Ibrahim, A.T. (1990). Hydatidosis. In: Human Health Hazard created by Animal Diseases. Khartoum University Press, pp:67-69.

[20] Katunguka, E. and Rubaire, C.M. (2008). Important Parasitic Diseases of Livestock in Uganda, Makerere University Press.

[21] Khuror, M.S. (2002). Hydatid disease: A current status and recent advances,

[22] Lightowlers, M., Flisser, A., Gauci, C., Heath, D., Jensen, O. and Rolfe, R. (2000). Vaccination against cysticercosis and hydatid disease. Parasitology Today, 16(5): 191-196. 
[23] Lightowlers, M., Lawrence, S., Gauci, C., Young, J., Ralston, M., Maas, D. and Heath, D. (1996). Vaccination against hydatidosis using a defined recombinant antigen. Parasite Immunology, 18(9): 457-462.

[24] Logar, J., Soba, B. and Kotar, T. (2008). Serological evidence for human cystic echinococcosis in Slovenia. BMC infectious diseases, 8(1): 63e.

[25] Lorenzo, C., Ferreira, H.B., Monteiro, K.M., Rosenzvit, M., Kamenetzky, L., García, H.H. and Lorca, M. (2005). Comparative analysis of the diagnostic performance of six major Echinococcus granulosus antigens assessed in a double-blind, randomized multicenter study. Journal of Clinical Microbiology, 43(6): 2764-2770.

[26] Macpherson, C., Bartholomot, B. and Frider, B. (2003). Application of ultrasound in diagnosis, treatment, epidemiology, public health and control of Echinococcus granulosus and E. multilocularis. Parasitology, 127(1): 21-35.

[27] Macpherson, C., Spoerry, A., Zeyhle, E., Romig, T. and Gorfe, M. (1989). Pastoralists and hydatid disease: an ultrasound scanning prevalence survey in East Africa. Transactions of the Royal Society of Tropical Medicine and Hygiene, 83(2): 243-247.

[28] Magambo, J., Njoroge, E. and Zeyhle, E. (2006). Epidemiology and control of echinococcosis in sub-Saharan Africa. Parasitology International, 55: 193-195.

[29] Magambo, J.K., Zeyhle, E. and Wachira, T. (1997). Hydatid disease in Toposa land southern Sudan. Afr. J. Health Sci., 5 (3-4):129-132.

[30] Magambo, J., Hall, C., Zeyle, E. and Wachira, T. (1996). Prevalence of human hydatid disease in southern Sudan. African Journal of Health Sciences, 3(4): 154-156.

[31] McManus, D.P., Zhang, W., Li, J. and Bartley, P.B. (2003). Echinococcosis. The Lancet, 362: 1295-1304.

[32] McManus, D.P. (2010). Echinococcosis with particular reference to Southeast Asia. Advances in Parasitology, 72: 267-303.

[33] Moro, P.S. (2006). Cystic echinococcosis in the Americas. Parasitology International, 55: (181186.)

[34] Njoroge, E.M., Magambo, J.K., Githaiga, L. and Zeyhle, E. (2001). A survey of C. Echinococcosis in South Sudan. Livestock Community and Environment. Proceedings of the $10^{\text {th }}$ Conference of the Association of Institutions for Tropical Veterinary Medicine, Copenhagen, Denmark.

[35] Ochi, E.B., Akol, D.A., Augustino, S.M. (2015).Prevalence and Economic Loss due to Hydatidosis in Slaughtered Animals in Juba South Sudan. International Journal of Research Studies in Biosciences, 3(3): 176-181.

[36] Omer, R.A., Daugschies, A. and Romig, T. (2011).Cystic Echinococcosis in Sudan and South Sudan. Research history of a neglected Zoonosis. Berliner und Münchener tierärztliche Wochenschrift, 124(11-12): 521-527.

[37] Polydorou, K. (1981), Animal Heath and economics. A case study; Echinococcosis with reference to Cyprus. Bul. Int. Epiz ., 93:981-992

[38] Romazanov, V.T. (1983). Evaluation of economic losses due to Echinococcosis. Zoonosis control: collection of teaching aids for international training course vol. II. Moscow: centre of international projects, pp 283-285.

[39] Sinan, T., Sheikh, M., Chisti, F.A., Al Saeed, O., Sheikh, Z., Hira, P. and Behbehani, A. (2002). Diagnosis of abdominal hydatid cyst disease: the role of ultrasound and ultrasound-guided fine needle aspiration cytology. Medical Principles and Practice, 11(4): 190-195.

[40] Soulsby, E.J.L. (1986).Genus: Echinococcus. In: Helminthes, Arthropods and Protozoa of Domesticated Animals, $7^{\text {th }}$ edition. The English Language Book Society and Bailliére Tindall. London. Pp:119-124.

[41] Stewart, B.T. , Jacob, J. , Finn, T. , Lado, M. , Napoleon, R. , Simon, B., Sidhu ,P.S. and Kolaczinski , J. (2013). Cystic echinococcosis in Mundari tribe-members of South Sudan. Pathogens and Global Health, 107 (6): 293-298. 
[42] Thomas, R.W., Ellis-Owen, R. and Winson, D. (2015).Secondary peritoneal hydatidosis, the challenges of echinococcal disease in South Sudan: a case report. The Pan African Medical Journal, 20:15e.

[43] Thompson, R., McManus, D., Eckert, J., Gemmell, M., Meslin, F. and Pawlowski, Z. (2001). WHO/OIE manual on echinococcosis in humans and animals: a public health problem of global concern. Eckert J, Gemmell MA, Meslin FX, Pawlowski ZSParis, France: World Organisation for Animal Health, 1-19.

[44] Torgerson, P.R. (2013). One world health: Socioeconomic burden and parasitic disease control priorities. Veterinary Parasitology, 195(3): 223-232.

[45] Torgerson, P.R. and Macpherson, C.N. (2011). The socioeconomic burden of parasitic zoonoses: global trends. Veterinary Parasitology, 182(1): 79-95.

[46] Torgerson, P. and Budke, C. (2003). Echinococcosis-an international public health challenge. Research in Veterinary Science, 74(3):191-202.

[47] Torgerson, P., Karaeva, R., Corkeri, N., Abdyjaparov, T., Kuttubaev, O. and Shaikenov, B. (2003). Human cystic echinococcosis in Kyrgystan: an epidemiological study. Acta Tropica, 85(1): 51-61.

[48] Toulah, F.H., El-Shafaeis, A.A. and Alsolami, M.N. (2012).Prevalence of Hydatidosis among slaughtered animals in Jeddah, Kingdom of Saudi Arabia. J. Egypt. Soc. Parasitol., 42 (3):563572 . 